\title{
A Circular Framework for Evaluating Highway Construction Projects Success: AHP Approach
}

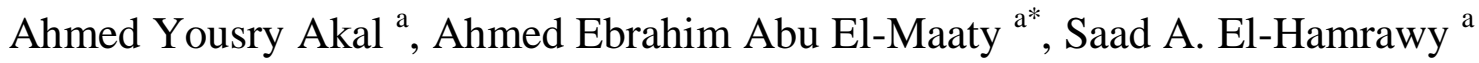 \\ ${ }^{a}$ Faculty of Engineering, Civil Engineering Department, Menoufia University, Shibin Elkom City, Egypt
}

Received 17 June 2016; Accepted 25 July 2016

\begin{abstract}
Success has always been the ultimate goal of every activity, and a construction project is no exception. There are few topics in the field of project management that are so frequently discussed and yet so rarely agreed upon as that the notion of project success criteria. Usually much of the national budget on infrastructure development is channelled to highway construction projects. However, no official studies have been presented before to evaluate the performance this industry in Egypt. Consequently, this reflects the importance of this study which aims at laying out a standard framework which identifies the criteria for measuring projects success. The identified criteria, in turn, can be used as a tool to help the stakeholders of the highway projects in Egypt in judging the project performance and success during the project's postconstruction phase. Using a detailed literature review thirteen success measures are identified (four objectives and nine subjective). Furthermore, the analytic hierarchy process (AHP) is adopted to prioritize the identified measures based on accumulative knowledge of academic experts in highways construction industry through the application of questionnaire survey. The study establishes that project completed on time, project completed within budget, health, safety and number of accidents, profitability and quality in construction are the most significant measures used for assessing the highway projects performance and success.
\end{abstract}

Keywords: Measures of Success; Construction Projects; Highway Projects; Analytic Hierarchy Process (AHP); Questionnaire Survey.

\section{Introduction}

Measurement is an essential step in any control process [1]. Indeed, "what gets measured gets done" [2]. The concept of measuring project success can be evaluated through performance measures that can be developed from reviewing previous studies where various success criteria can be identified [3]. Lim and Mohamed (1999) [4] defined criteria as "set of principles or standards by which judgment is made and are considered to be the rule of the game". Success has always been the ultimate goal of every activity and a construction project is no exception [3]. Due to the ambiguous definition of project success and the different perceptions of participants toward this concept, measuring project success is a complex task since success is intangible and can hardly be agreed upon for all stakeholders during all phases in the project life cycle. For instance, the architect may consider the aesthetics aspect as the project success criterion, while the contractor may rank profitability the most important factor. In addition, a project may be perceived a success one day and failure the next. Therefore, to think that one can objectively measure the success of a project is an illusion [3,5]. One of the most widely used project performance measure has been the 'iron triangle' consisting of schedule, cost and quality at the three vertices [6]. With the passage of time, other criteria have been also proposed to measure a project's performance. These performance measures can be characterized into objective and subjective categories. In the objective criteria we have tangible and measurable performance measures such as: schedule, cost, quality, safety and dispute while in the subjective criteria we have client satisfaction, contractor satisfaction and project management team satisfaction [5]. A summary of the success criteria used by different researchers is presented in Table 1. The present study seeks to identify the objective and subjective measures of success which can be used for evaluating the performance of highway construction projects in Egypt during the project post-construction phases.

\footnotetext{
*Corresponding author: maaty5000@yahoo.com
} 
Moreover, it aims at prioritizing and ranking the identified measures based on accumulative knowledge and judgment of experts in highway construction industry in Egypt through the application of the analytical hierarchy process (AHP).

Table 1. Summary of success criteria

\begin{tabular}{ll}
\hline \multicolumn{1}{c}{ Success Criteria } & Reference \\
\hline $\begin{array}{l}\text { Time, cost, performance, use, satisfaction and effectiveness } \\
\text { Construction time, speed of construction, unit cost, percentage net variation over final }\end{array}$ & Pinto and Slevin [7] \\
cost, client's satisfaction on cost, time, quality, functionality and overall satisfaction, & Chan [8] \\
designer's overall satisfaction and contractor's overall satisfaction & \\
$\begin{array}{l}\text { Project efficiency, impact on the customer, direct and business success and preparing for } \\
\text { the future }\end{array}$ & Shenhar, Levy, and Dvir [9] \\
$\begin{array}{l}\text { Meeting design goals, benefits to the customer, benefits to the developing organization } \\
\text { and benefits to the defense and national infrastructure }\end{array}$ & $\begin{array}{l}\text { Lipovetsky, Tishler, Dvir and } \\
\text { Budget, schedule, meets specification, conforms to user's expectation, high quality of } \\
\text { workmanship and minimizes construction aggravation }\end{array}$ \\
$\begin{array}{l}\text { Budget, financial performance and profitability } \\
\text { Time and cost, quality and productivity/efficiency }\end{array}$ & Norris [12] \\
$\begin{array}{l}\text { Time and cost, budget/financial performance/profitability, health and safety, quality, } \\
\text { meeting technical performance, specification and functionality, satisfaction } \\
\text { client/customer, contractor, project manager/team satisfaction, expectation/aspiration of } \\
\text { client/contractor project manager/team and satisfaction }\end{array}$ & Parfitt and Sanvido [14]
\end{tabular}

\section{Literature Review}

Several studies have been carried out in order to develop criteria for measuring construction project success and every researcher came up with his/her methodology in identifying these measures. Baccarini (1999) [15] used the logical framework method as a foundation for defining the criteria for measuring project success. The results of the study showed that project management success has three components: a) meeting time, cost and quality objectives (project outputs and inputs); b) quality of the project management process; and c) satisfying project stakeholder's needs where they relate to the project management process. Freeman and Beale (1992) [16] in the review of a project management literature, identified seven major criteria for measuring the success of projects. Five of these criteria are frequently used: technical performance; efficiency of execution; managerial and organizational implications (mainly customer satisfaction); personal growth; and manufacturability and business performance.

Rowlinson (1988) [17] conducted a study in the United Kingdom on 27 industrial buildings to identify the variables which led to the systematic difference in the performance achieved during industrial building projects. He found that the procurement form was not a good predictor of success. The general management variables, such as the client organisation, the nature of the project, the organisation of the building team and its management, were found to be much better predictors of success. A study by Baker et al. (1983) [18] strongly confirmed the importance of including client satisfaction within any measure of project success. After sampling over 650 project managers, the researchers concluded that project success is something much more complex than simply meeting cost, schedule and performance specifications. In fact, client satisfaction with the final product had a close connection to the perceived success or failure of the project.

Furthermore, the variety of measures used to assess project success has led some researchers to group these measures into several distinct clusters with common underlying dimensions. For instance, Cooper and Kleinschmidt (1987) [19] used the factor analysis technique to identify three different dimensions of the project: financial performance, opportunity window and new market area. Pinto and Mantel (1990) [20], based on a literature survey and after interviews of experienced project managers, reached a similar conclusion. They identified three distinct aspects of project performance as benchmarks against which the success or failure of a project can be assessed: the implementation process, the perceived value of the project and client satisfaction.

According to the above review of previous studies, it can be noted that there is a plenty of measures which can be used to assess the project success. Criteria for measuring project success mean different things to different people. Furthermore, success measures may change over time from country to country. In addition, the project success is influenced to a high degree by the project type, the project size and the project participants. Accordingly, to set a fixed and unified concept of these criteria is a very complex task. However, the study of these criteria is still very important for all researchers who are interested in the development of construction industry. 


\section{Importance of the Study}

The construction industry in Egypt accounts for 4.7\% of Egypt's Gross Domestic Product, making it one of the most important industries for the country's economic progress [21]. The investments in infrastructure especially highway project reach to US $\$ 5.46$ billion which means that much of the national budget on infrastructure development is channelled to highway construction projects [22, 23]. However, no official reports or studies have been presented before to evaluate the performance such industry in Egypt. Consequently, this reflects the importance of the present study which aims at providing the stakeholders of the highway projects in Egypt with a tool in order to be used in judging these projects' performance and success.

\section{Study Methodology}

For the purpose of providing the stakeholders of the highway projects with the measures of success in order to be used in judging the project performance through the application of AHP technique, five steps have been designed to clearly illustrate the study methodology. The first step of the methodology aims at reviewing the previous literature regarding the AHP theory and measures of success. While, the second one seeks to identify the measures of success considered in the present study. Step three has been provided in order to show how the hierarchy model of the success measures has been structured. Furthermore, step four has been designed to illustrate the questionnaire survey content. Finally, step five analyzed and discussed the survey results in order to prioritize and rank the identified success measures of the current study. Figure 1. summarizes the steps of the study methodology.

\subsection{Criteria for Measuring Project Success}

According to the viewpoints of the majority of the researchers regarding the issue of project success criteria, it can be indicated that research on project success should incorporate both objective and subjective performance measures [3, 5 and 8$]$. In the present study, the objective measures adopted in order to represent the tangible criteria are:
a) Project completed on time
b) Project completed within budget
c) Profitability
d) Health, safety and number of accidents

While, the subjective measures concerned with the intangible criteria are:
a) Quality in construction
b) Meeting the specifications
c) Functionality / fitness for the purpose
d) Fulfilling end-user needs
e) Satisfaction
f) Absence of conflicts / legal claims
g) Environmental sustainability
h) Aesthetic value
i) Develop new knowledge and expertise

Figure 2. shows the adopted cycle framework for measuring projects success. 


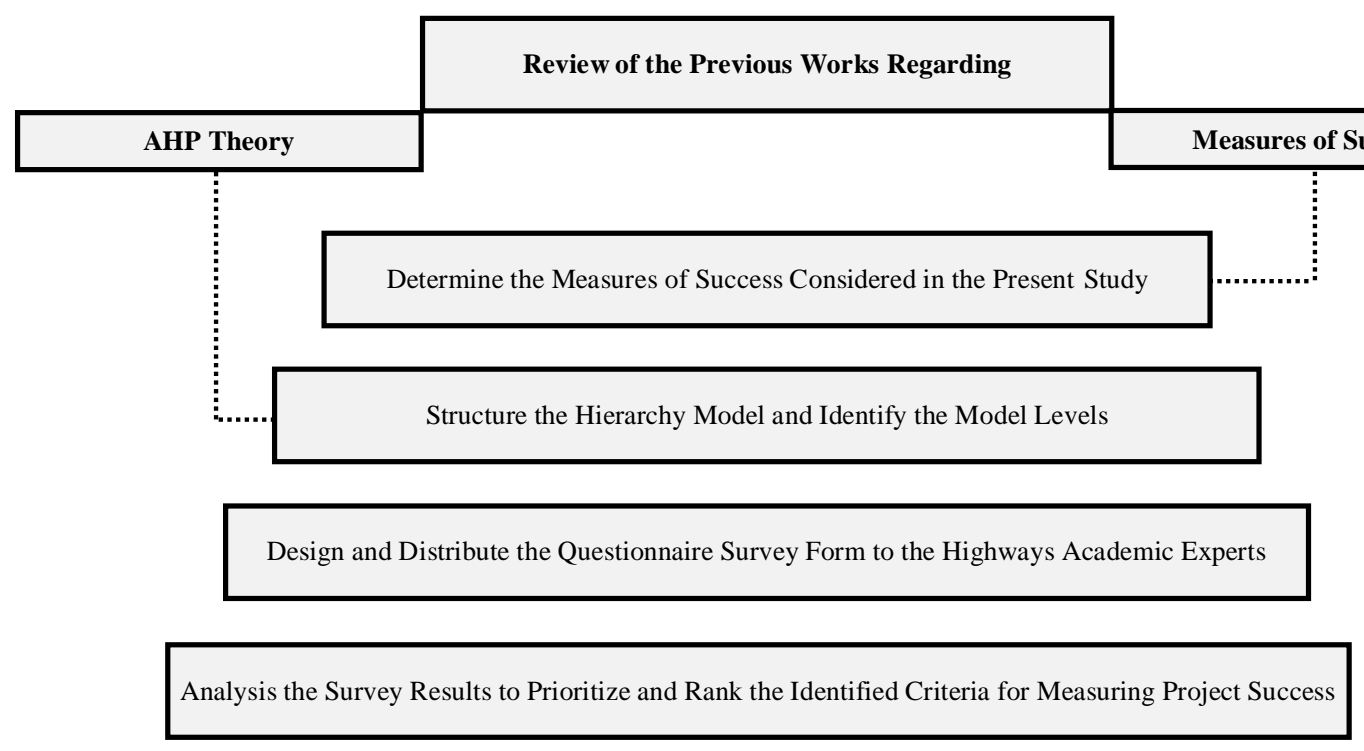

Figure 1. Methodology flowchart

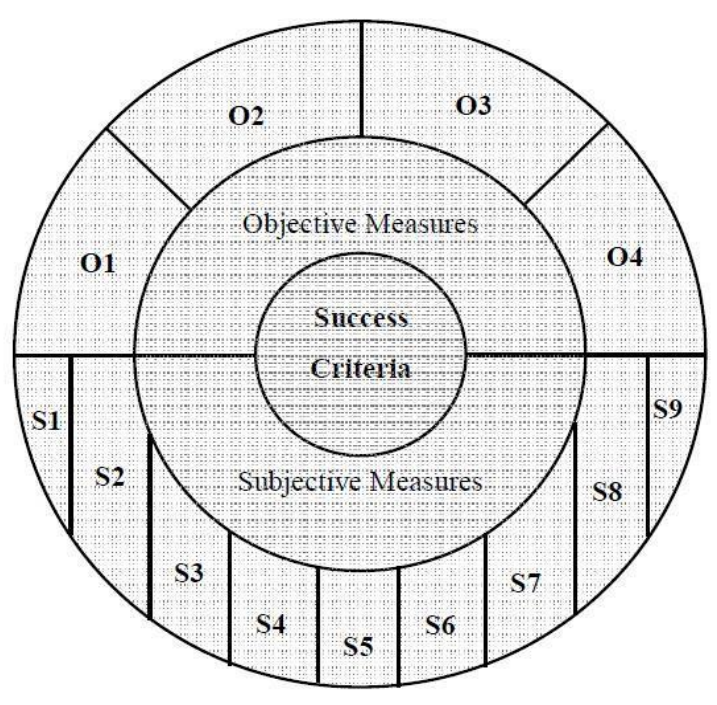
Legend of the success criteria:
O1 Project completed on time
O2 Project completed within budget
O3 Profitability
O4 Health, safety and number of accidents
S1 Quality in construction
S2 Meeting the specifications
S3 Functionality/fitness for the purpose
S4 Filling end-user needs
S5 Satisfaction
S6 Absence of conflicts/legal claims
S7 Environmental sustainability
S8 Aesthetic value
S9 Develop new knowledge and expertise

Figure 2. Cycle framework for measuring projects success

\subsection{Analytic Hierarchy Process}

The Analytic Hierarchy Process (AHP) was firstly introduced in the early 1970s by Thomas Saaty to be used for dealing with complex technological, economic and socio-political problems [24]. AHP helps in identifying priorities on the basis of the decision-maker's knowledge and experience of each problem. The strength of AHP lies in its ability to structure a complex, multi-person, multi-criteria problem hierarchically and then to investigate each level separately, combining the results as the analysis progresses [25]. The AHP theory depends on breaking down the decision problem into elements, according to their common characteristics and levels, which correspond to the common characteristic of the elements. The topmost level is the focus of the problem or the ultimate goal; the intermediate levels correspond to criteria and sub-criteria, while the lowest level contains the decision alternatives [26]. Figure 3. shows an example of hierarchy structure. 
Level One

Focus

Level Two

Decision Criteria

Level Three

Decision Sub-Criteria

\section{Level K}

Alternatives

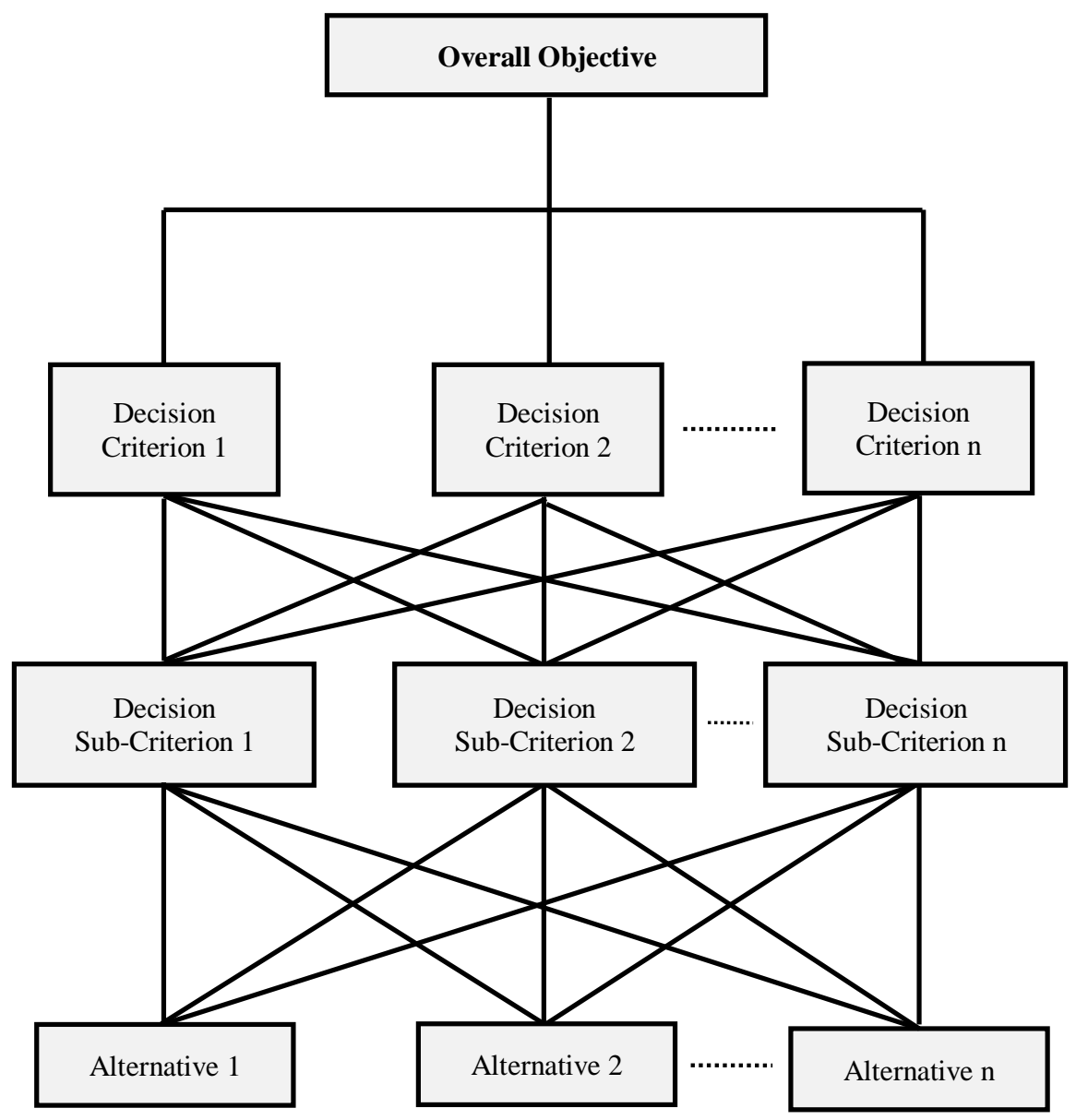

Figure 3. Hierarchy Structure Example [27]

Furthermore, AHP depends on using the pairwise comparison in establishing the priorities of the elements at the same level i.e. criteria and alternatives [28]. The pairwise comparisons are guided by a nine-point scale as depicted in Table 2 [29]. Adopting the nine-point scale, the experts would be able to express their judgment subjectively. Hence it is possible to make comparisons between tangible and intangible factors [30].

Table 2. Fundamental scale of absolute numbers [29]

\begin{tabular}{cc}
\hline Intensity of Importance & Definition \\
\hline 1 & Equal importance \\
3 & Weak importance of one over another \\
5 & Essential or strong importance \\
7 & Very strong or demonstrated importance \\
9 & Absolute importance \\
$2,4,6,8$ & Intermediate values between adjacent scale values \\
\hline
\end{tabular}

\subsubsection{Analytic Hierarchy Process}

As for the purpose of the present study, the hierarchy model for measuring project success as shown in Figure 4. is consisted of three levels. At the top of the hierarchy is the goal of "criteria for measuring project success". Furthermore, level two represents the objective and subjective measures. Finally, the thirteen criteria which have been identified to measure the project success are allocated to level three of the hierarchy. 


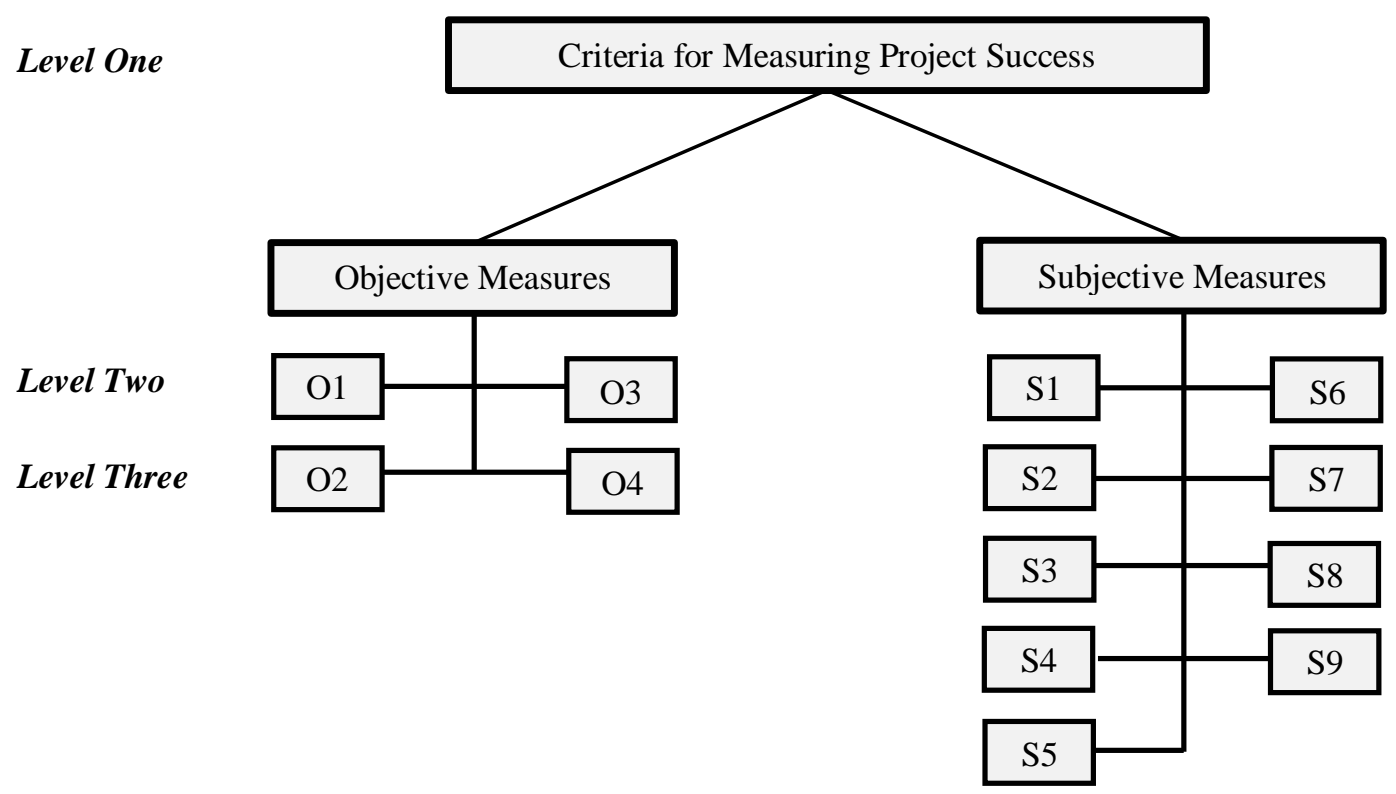

Figure 4. The hierarchy model of the success measures

\subsection{Questionnaire Design and Distribution}

The research method of this study is mainly based on a structured questionnaire survey in order to meet the requirements of the research objectives and achieve better results. The developed questionnaire has been designed in order to specify the relative importance weight of the suggested success measures to judge the highway projects performance through the application of AHP numerical rating. The questionnaire has been divided into three sections as follows:

- Section No. 1: Personal information about the respondents: this part of the questionnaire consists of four questions which have been set to ask for information about the respondents such as his/ her name (optional) and relevant working experience.

- Section No. 2: Guideline for filling and establishing the importance weight: this part of the questionnaire illustrates how the participants can use the AHP in the bases of pairwise comparison to determine the importance weight of the suggested measures in the questionnaire.

- Section No. 3: Success measures for judging the highway projects performance: this section presents the objective and subjective suggested measures to judge the highway projects performance.

After determining the questionnaire objectives and designing its sections, the designed questionnaire has been distributed to academic experts. Five academic experts have been selected to prioritize the suggested success measures. All the respondents have been selected based on their experience in the industry of highway projects in Egypt. It is noteworthy that all the respondents have over 10 years of experience with a qualification of a PHD degree.

The relatively small sample size is mainly attributed to two reasons. First, only those with about 10 years of experience would be approached to preserve the quality of the opinions gathered in the survey. This has significantly reduced the pool size of the potential respondents. Second, some of the experienced practitioners contacted were reluctant to participate in the survey because of the commitment expected from them, bearing in mind that they have to make pairwise comparisons of 13 success-related measures.

To secure good quality data, a separate personal interview with every academic expert has been conducted in order to facilitate the process of filling in the questionnaire. After two months of following up with the participants, all the academic experts fill in and send the questionnaires by mail. Then the returned questionnaires have been entered into computer spreadsheets in order to be used for determining the importance weight of the identified measures of success.

\subsection{Relative Importance Weight Calculation}

By following AHP steps as clearly described in details by Al Wahaidi (2012) [31], the importance weight of the success measures can be easily determined. The following example provides a step-by-step illustration of how the 
relative importance weight of each measure can be calculated. Table 3 shows the pairwise comparison matrix of the objective success measures according to the perspective one academic expert.

Table 3. Pairwise comparison matrix of the objectives success measures by one expert

\begin{tabular}{ccccc}
\hline & O1 & O2 & O3 & O4 \\
\hline $\mathbf{O 1}$ & 1 & 4 & 2 & $1 / 3$ \\
$\mathbf{O 2}$ & $1 / 4$ & 1 & 3 & 3 \\
$\mathbf{O 3}$ & $1 / 2$ & $1 / 3$ & 1 & 3 \\
$\mathbf{O 4}$ & 3 & $1 / 3$ & $1 / 3$ & 1 \\
\hline
\end{tabular}

Table 4 shows the synthesized matrix of the objective success measure by one expert. The synthesized matrix is structured by dividing each element of the pairwise comparison matrix on its column's total. For instance, the value 0.21053 in the first row in Table 4 is obtained by dividing 1 from Table 3 by the sum of the first column items in Table 3 and so forth. On the other hand, the importance weight in Table 4 is determined by finding the row averages. For instance, the importance weight of the "O1" is calculated by dividing the sum of the first row in Table 3 $(0.21053+0.70597+0.31581+0.04541)$ by the number of columns, i.e., 4 , in order to obtain the value of 0.31943 .

Table 4. Synthesized matrix of the objectives success measures by one expert.

\begin{tabular}{cccccc}
\hline & $\mathbf{O 1}$ & $\mathbf{O 2}$ & $\mathbf{O 3}$ & $\mathbf{O 4}$ & Weight \\
\hline $\mathbf{O 1}$ & 0.21053 & 0.70597 & 0.31581 & 0.04541 & 0.31943 \\
$\mathbf{O 2}$ & 0.05263 & 0.17649 & 0.47371 & 0.40911 & 0.27798 \\
$\mathbf{O 3}$ & 0.10526 & 0.05877 & 0.1579 & 0.40911 & 0.18276 \\
$\mathbf{O 4}$ & 0.63158 & 0.05877 & 0.05258 & 0.13637 & 0.21983 \\
\hline
\end{tabular}

By following the illustrated steps, the synthesized matrices, the importance weights for the remaining success measures can be easily determined.

\section{Findings and Results}

This section discusses the results of the questionnaire survey in order to determine the priorities and ranking of the identified measures of success according to the viewpoints of five academic experts in highways construction industry in Egypt. In the current study the ranking process will be determined with respect to the local and global weights of the studied measures. The Local weight can be derived from judgment in relation to a single criterion. While, the global weight is derived from multiplying the weight of the criteria.

Figures 5 and 6 show the local weights of the objective and subjective success measures respectively. The analysis of these Figures confirm that Factor No. O1"project completed on time" with local weight $=0.3329$ can be used as a objective measure for assessing the performance of the highway projects in Egypt. While, Factor No. S1"quality in construction" with local weight $=0.2460$ can be used as a subjective measure for evaluating the success of highway projects in Egypt.

Figure 7. display the global weights of the success measures. The results of this Figure indicate that the most five significant success measures which can be used for assessing the project performance and the project success during the project post-construction phase are Factor No. O1"project completed on time" Factor No. O2, "project completed within budget", Factor No. O4 "health, safety and number of accidents", Factor No. O3 "profitability" and Factor No. $\mathrm{S} 1$ "quality in construction" with global weights $=0.2457,0.207,0.1692,0.1198$ and 0.0631 respectively. 


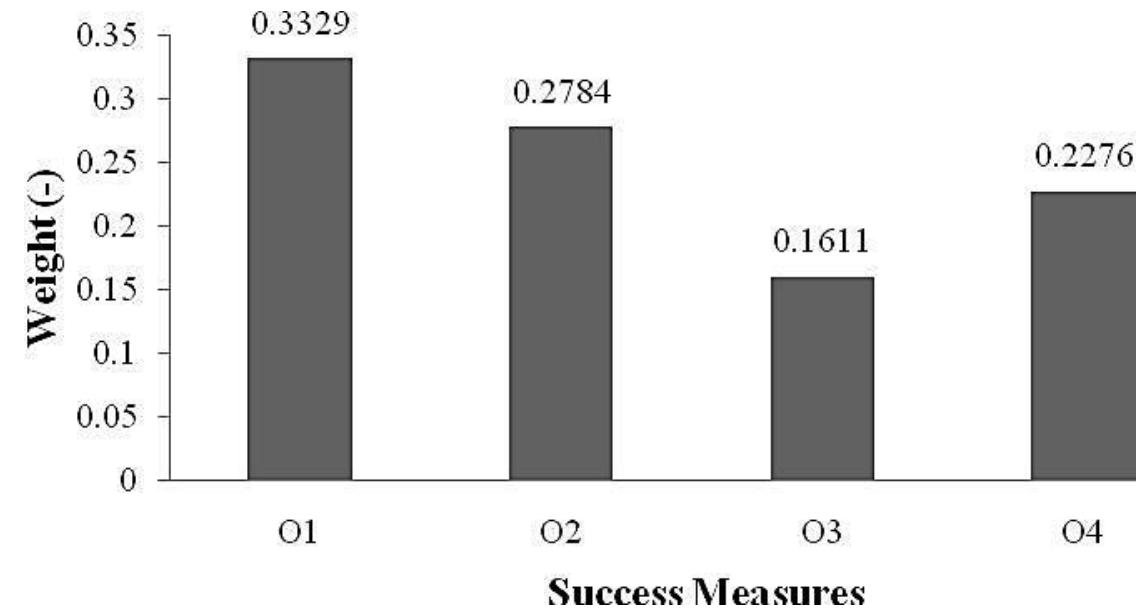

Figure 5. Local weights of the objective success measures

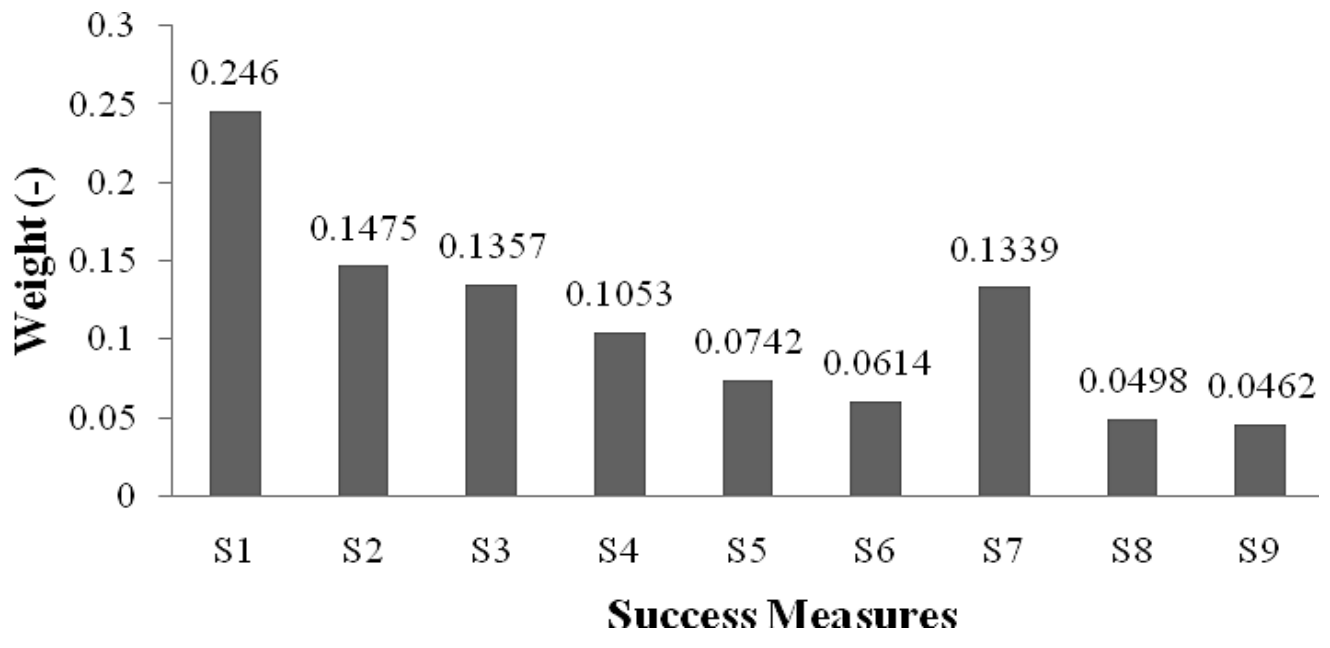

Figure 6. Local weights of the subjective success measures

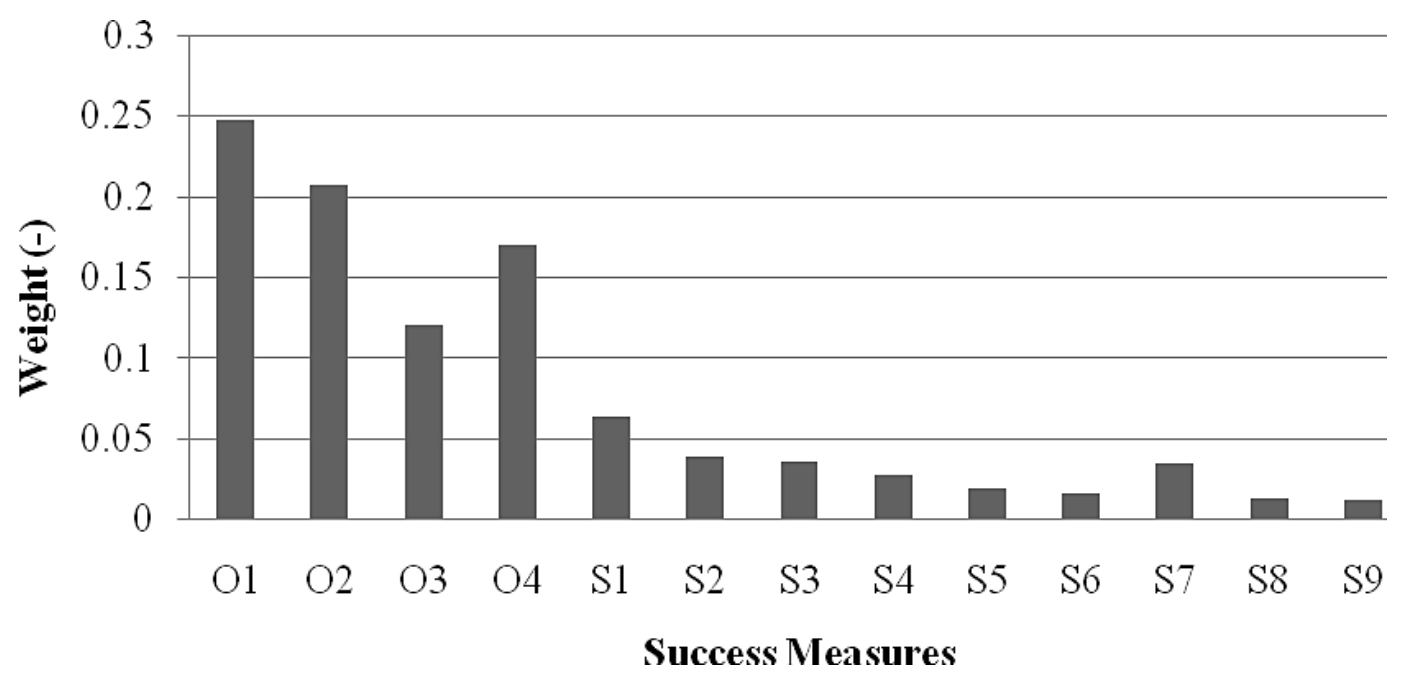

Figure 7. Global weights of the success measures 


\section{Summary and Conclusions}

The present study has adopted the AHP method to determine the priority of 13 success measures which are identified through a detailed literature review. The identified criteria have been divided into two groups one contains four objective success measures and the other one contains nine subjective measures. Through a questionnaire survey which has been sent to five academic experts in highway construction industry in Egypt, the importance weight of the success measures has been specified and it has been noted that:

- Project completed on time and quality in construction have been suggested as the most important objective and subjective measures respectively.

- Project completed on time, project completed within budget, health, safety and number of accidents, profitability and quality in construction have been ranked as the most important measures which could be used for assessing the performance of highway construction projects in Egypt.

Further research can be carried out with a greater number of respondents. With a greater number of respondents, more meaningful comparisons can be made by analyzing the results according to organizational backgrounds of the respondents, types of project, etc. Similar research may also be conducted with respect to construction activities in other countries, using the present findings as the basis for research framework and comparison.

\section{References}

[1] Chang, A. S., and Ibbs, C. W. "Development of Consultant Performance Measures for Design Projects." Project Management Journal, Vol. 29, No. 2, 39-54, (1998).

[2] Ledbetter, W. "Quality Performance on Successful Project." Journal of Management in Engineering, Vol. 120, No. 1, 34-64, (1994).

[3] Chan, A. P. C., Scott, D. and Lam, E. "Framework of Success Criteria for Design/Build Projects." Journal of Management in Engineering, Vol. 18, No. 3, 120-128, (2002).

[4] Lim, C. S. and Mohamed, M. Z. "Criteria of Project Success: An Exploratory Re-Examination." International Journal of Project Management Vol. 17, No. 4, 243-248, (1999).

[5] Jha, K.N. "Determinants of Construction Project Success in India." Vol. 23, Springer, Dordrecht, Netherlands (2013).

[6] Atkinson, R. "Project Management: Cost, Time and Quality, Two Best Guesses and a Phenomenon, it's Time to Accept other Success Criteria." International Journal of Project Management, Vol. 17, No. 6, 337-342, (1999).

[7] Pinto, J. and Slevin, D. "Project Success: Definitions and Measurement Techniques." Project Management Journal, 67-72, (1988).

[8] Chan, A.P.C. "Determinants of Project Success in the Construction Industry of Hong Kong." PhD Thesis, The International Centre for Management and Organisational Effectiveness, Faculty of Business and Management, University of South Australia, Australia (1996)

[9] Shenhar, A. J., Levy, O. and Dvir, D. "Mapping the Dimensions of Project Success." Project Management Journal, Vol. 28, No. 2, 5-13, (1997).

[10] Lipovetsky, S., Tishler, A., Dvir, D. and Shenhar, A. "The Relative Importance of Project Dimensions." R\&D Management, Vol. 27, No. 2, 97-106, (1997).

[11] Songer, A. D. and Molenaar, K. R. "Project Characteristics for Successful Public Sector Design-Build." Journal of Construction Engineering and Management, Vol. 123, No. 1, 34-40, (1997).

[12] Norris, W. E. "Margin of Profit: Teamwork." Journal of Management in Engineering, Vol. 6, No. 1, 20-28, (1990).

[13] Maloney, W. F. "Framework for Analysis of Performance." Journal of Construction Engineering and Management, Vol. 116, No. 3, 399-415, (1990).

[14] Parfitt, M. K., and Sanvido, V. E. "Checklist of Critical Success Factors for Building projects." Journal of Management in Engineering, Vol. 9, No. 3, 243-249, (1993).

[15] Baccarini, D. "The Logical Framework Method for Defining Project Success." Project Management Journal, PMI, 25-32, (1999).

[16] Freeman, M. and Beale, P. "Measuring Project Success. "Project Management Journal, PMI, 8-17, (1992).

[17] Rowlinson, S.M. "An analysis of Factors Affecting Project Performance in Industrial Building." PhD Thesis, Brunel 
University, UK, (1988).

[18] Baker, B.N, Murphy, D.C. and Fisher, D. "Factors Affecting Project Success." In Cleland, D.I. and King, W.R. (eds.) Project Management Handbook. New York: Van Nostrand Reinhold (1983).

[19] Cooper, R.G. and Kleinschmidt, E.J. "Success Factors in Product Innovation.” Industrial Marketing Management, Vol. 16, No. 3, 215-224, (1987).

[20] Pinto, J.K. and Mantel, S.J. “The Causes of Project Failure.” IEEE Transactions on Engineering Management, Vol. 37, No. 4, 269, 276, (1990).

[21] Timetric "Construction in Egypt - Key Trends and Opportunities to 2016." http://www.marketresearch.com/Timetricv3917/Construction-Egypt-Key-Trends-Opportunit es-7084362, Accessed on October 23, 2013.

[22] PWC's Staff Reporter "Africa Gearing up-Future Prospects in Africa for the Transportation \& Logistics Industry." http://www.pwc.com/africagearingup, Accessed on March 13, 2013.

[23] Kaliba, C., Muya, M. and Mumba, K. (2009). "Cost Escalation and Schedule Delays in Road Construction Projects in Zambia.” International Journal of Project Management, Vol. 27, No. 5, 522-531.

[24] Saaty, T. L. (1980). "The Analytic Hierarchy Process: Planning, Priority Setting, Resources Allocation." McGraw-Hill, London, England.

[25] Oguztimur, S. "Why Fuzzy Analytic Hierarchy Process Approach for Transport Problems?." Proceedings of the ERSA Congress, Barcelona, Spain (2011).

[26] Berrittella, M., Certa, A., Enea, M., and Zito, P. “An Analytic Hierarchy Process for the Evaluation of Transport Policies to Reduce Climate Change Impacts.” Fondazione Eni Enrico Mattei Working Papers, Paper 61, (2007).

[27] Saaty, T. L. "Fundamentals of Decision Making and Priority Theory with the Analytic Hierarchy Process" Vol. VI, RWS Publications, Pittsburgh, USA, (1994).

[28] Kaliba, C. "Cost Escalation, Schedule Overruns and Quality Shortfalls on Construction Projects." M.S. Thesis, Department of Civil and Environmental Engineering, School of Engineering, University of Zambia, Lusaka, Zambia (2010).

[29] Saaty, T. L. "Decision Making with the Analytic Hierarchy Process." International Journal of Services Sciences, Vol. 1, No. 1, 83-98 (2008).

[30] Chua, D. K. H., Kog, Y. C. and Loh, P. K. “Critical Success Factors for Different Project Objectives.” Journal of Construction Engineering and Management, Vol. 125, No. 3, 142-150 (1999).

[31] Al Wahaidi, S.Y. “An Analytical Hierarchy Process (AHP) Based Prequalification System for Gaza Strip Construction Contractors. " M.S. Thesis, Faculty of Engineering, Islamic University, Gaza, Palestine, (2012). 